\title{
Article \\ Effects of Hyperbaric Oxygen Therapy on Serum Adhesion Molecules, and Serum Oxidative Stress in Patients with Acute Traumatic Brain Injury
}

\author{
Hung-Chen Wang ${ }^{1,+}$, Pei-Ming Wang ${ }^{2,+}$, Yu-Tsai Lin ${ }^{3,4}{ }^{\mathbb{D}}$, Nai-Wen Tsai ${ }^{5}$, Yun-Ru Lai ${ }^{5}$, Chia-Te Kung ${ }^{6}$, \\ Chih-Min $\mathrm{Su}^{6}{ }^{\mathbb{D}}$ and Cheng-Hsien $\mathrm{Lu}^{5,7,8, *}$
}

1 Departments of Neurosurgery, Kaohsiung Chang Gung Memorial Hospital and Chang Gung University College of Medicine, Kaohsiung 833401, Taiwan; m82whc@yahoo.com.tw

2 Departments of Family Medicine, Kaohsiung Chang Gung Memorial Hospital and Chang Gung University College of Medicine, Kaohsiung 833401, Taiwan; wangpeming@yahoo.com.tw

3 Departments of Otolaryngology, Kaohsiung Chang Gung Memorial Hospital and Chang Gung University College of Medicine, Kaohsiung 833401, Taiwan; whc8131977@gmail.com

4 Graduate Institute of Clinical Medical Sciences, College of Medicine, Chang Gung University, Taoyuan City 33302, Taiwan

5 Departments of Neurology, Kaohsiung Chang Gung Memorial Hospital and Chang Gung University College of Medicine, Kaohsiung 833401, Taiwan; tsainw@yahoo.com.tw (N.-W.T.); yunru.lai@gmail.com (Y.-R.L.)

6 Departments of Emergency Medicine, Kaohsiung Chang Gung Memorial Hospital and Chang Gung University College of Medicine, Kaohsiung 833401, Taiwan; kungchiate@gmail.com (C.-T.K.); mitosu@gmail.com (C.-M.S.)

check for updates

Citation: Wang, H.-C.; Wang, P.-M.; Lin, Y.-T.; Tsai, N.-W.; Lai, Y.-R.; Kung, C.-T.; Su, C.-M.; Lu, C.-H. Effects of Hyperbaric Oxygen Therapy on Serum Adhesion Molecules, and Serum Oxidative Stress in Patients with Acute Traumatic Brain Injury. J. Pers. Med. 2021, 11, 985 . https://doi. org/10.3390/jpm11100985

Academic Editor: Sabina Tangaro

Received: 5 September 2021

Accepted: 27 September 2021

Published: 29 September 2021

Publisher's Note: MDPI stays neutral with regard to jurisdictional claims in published maps and institutional affiliations.

Copyright: (c) 2021 by the authors. Licensee MDPI, Basel, Switzerland. This article is an open access article distributed under the terms and conditions of the Creative Commons Attribution (CC BY) license (https:/ / creativecommons.org/licenses/by/ $4.0 /)$.
7 Department of Biological Science, National Sun Yat-sen University, Kaohsiung 80424, Taiwan

8 Department of Neurology, Xiamen Chang Gung Memorial Hospital, Xiamen 361126, China

* Correspondence: chlu99@ms44.url.com.tw; Tel.: +886-7-7317123 (ext. 8011)

+ Hung-Chen Wang and Pei-Ming Wang contributed equally to this study as co-first authors.

Abstract: Background: Serum concentrations of adhesion molecules and oxidative stress is thought to participate in the pathobiology of secondary brain injury after acute traumatic brain injury (TBI). We aimed to study the hypothesis that hyperbaric oxygen therapy (HBOT) both improves the adhesion molecules levels and antioxidant capacity. Methods: Thirty blood samples from ten patients after acute TBI were obtained after injury and before and after HBOT. Four patients received early HBOT started two weeks after injury, four patients received late HBOT started ten weeks after injury and two patients did not receive HBOT and served as control in this study. The HBOT patients received total 30 times HBOT in six weeks period. Results: Those serum biomarkers in patients with TBI had not significantly difference in glutathione (GSH), thiobarbituric acid reactive substances (TBARS), soluble intercellular cell adhesion-molecule-1 (sICAM-1) and soluble vascular cell adhesion molecule-1 (sVCAM-1) concentrations on admission between early HBOT, late HBOT, and control group ( $p=0.916, p=0.98, p=0.306$, and $p=0.548$, respectively). Serum GSH levels were higher at 10 weeks after injury in the early HBOT group than in the late HBOT group and control group (mean, $1.40 \mu \mathrm{mol} / \mathrm{L}, 1.16 \mu \mathrm{mol} / \mathrm{L}$, and $1.05 \mu \mathrm{mol} / \mathrm{L}$, respectively). Then the serum GSH level was increased at 18 weeks after injury in the late HBOT group (mean, $1.49 \mu \mathrm{mol} / \mathrm{L}$ ). However, there was only statistically significant difference at Weeks $18(p=0.916, p=0.463$, and $p=0.006$, at Week 2, Week 10, and Week 18, respectively). Serum TBARS levels were decreased at 10 weeks after injury in the early HBOT group than in the late HBOT group and control group (mean, $11.21 \mu \mathrm{mol} / \mathrm{L}$, $17.23 \mu \mathrm{mol} / \mathrm{L}$, and $17.14 \mu \mathrm{mol} / \mathrm{L}$, respectively). Then the serum TBARS level was decreased at 18 weeks after injury in the late HBOT group (mean, $12.06 \mu \mathrm{mol} / \mathrm{L}$ ). There was statistically significant difference after HBOT ( $p=0.98, p=0.007$, and $p=0.018$, at Week 2, Week 10, and Week 18, respectively). There was no statistically significant difference between the three groups on sICAM-1 and sVCAM-1 levels from Week 2 to Week 18. Conclusions: HBOT can improve serum oxidative stress in patients after TBI. These molecules may be added as evaluation markers in clinical practice. Perhaps in the future it may also become part of the treatment of patients after acute traumatic brain injury. Further large-scale study may be warrant. 
Keywords: traumatic brain injury; hyperbaric oxygen therapy; oxidative stress; adhesion molecules

\section{Introduction}

Acute traumatic brain injury (TBI) is a disease process with an initial injury, involves inflammatory pathways activation, and contributes to continuing biochemical and cellular changes over time [1,2]. The brain has the highest oxygen metabolism rate among the organs of the body [3]. This high rate of oxygen metabolism leads to the possibility of excessive reactive oxidative stress (ROS) production. A large amount of ROS causes oxidative stress have been suggested to play a crucial role in the pathology of TBI, and several cell characteristics of the brain indicate that it is highly sensitive to oxidative stress. An imbalance of ROS generation and the oxidative metabolism which leads to mitochondrial dysfunctions and apoptosis [4], and that apoptotic factor in different brain regions of rats might contribute to neurotoxicity [5]. Brain tissue contains a lot of unsaturated fatty acids and iron, which can be metabolized by oxygen free radicals [6,7]. In scavenging oxygen free radicals, the brain has only $10 \%$ of the catalase activity in the liver [7]. Thus, compared with other body organs, the brain's defense system against oxidative stress may be insufficient. Evidence from animal TBI models shows that ROS production increases immediately within a few minutes after injury [8-10]. Previous reports showed that excess oxidative stress can affect energy metabolism [4], block the electron transport chain of mitochondria and damage to neurocytes and cerebrovascular endothelium [11] causing neurotoxicity such as apoptosis [12-14]. Scavenging of ROS after TBI can reduce brain damage in rat [15].

There is growing evidence show that TBI can trigger systemic inflammation and coagulation cascades, leading to secondary neuropathological sequelae $[16,17]$. Vascular endothelium provides a key interface for the host's inflammation and coagulation response to injury. These responses are related to the activation of resident and peripheral macrophages [18-21], and the activation of inflammatory cytokines, and adhesion molecules [22-25]. Inflammation cells marginalized along the vessel wall is mediated by adhesion to endothelial ligands for soluble intercellular (sICAM-1) and soluble vascular cell adhesion molecules (sVCAM-1), which allows leukocyte migration into the injured tissues [26]. Several clinical studies have demonstrated significant elevation of adhesion molecules in acute brain injury $[27,28]$.

It is well documented that hyperbaric oxygen therapy (HBOT) has neuroprotective effects against damaged brain tissue [29-34]. Although HBOT had no effect to treat cognitive, or fine motor deficits associated in patients with mild TBI and post-concussive symptoms [32,34]. Some animal studies revealed that HBOT had the beneficial effect of on the injured brain and improved cognitive function [35-38]. Till now, little is known about the effects of HBOT on time course of oxidative stress concentration and soluble endothelial adhesion molecules changes in acute TBI patients. This prospective study aimed to evaluate the effects of HBOT on serial oxidative stress and adhesion molecular levels in patients with acute TBI.

\section{Materials and Methods}

\subsection{Patients}

The diagnosis of acute TBI is confirmed by medical history and computed tomography (CT) scan of the brain. Patients were excluded if they: (1) were taking anti-platelet or anticoagulant; (2) penetrating head injury; (3) central nervous system infection; (4) had major systemic diseases like malignant tumor, end-stage renal disease, liver cirrhosis, congestive heart failure.

This study included mild and moderate (GCS $\leqq 9$ ) traumatic brain injuries. The age of the patients was range 18-65 years. Patients will be included in this study only if they have obtained the fully informed written consent of the patients or their family members and meet the above diagnostic criteria. Patients were assigned to different groups by principal 
investigator based on patient's clinical condition. If patient was suitable to do HBOT, he was assigned by randomizing. If patient's condition was not suitable to do HBOT in acute phase, he was assigned to late HBOT group, and if patient hesitated to do HBOT, he was assigned to No HBOT group. The informed consent will be approved by the Ethics Committee of our hospital. A total of ten adult patients were included in the study.

\subsection{Hyperbaric Oxygen Therapy (HBOT)}

During HBOT, patients were placed in a chamber and were pressurized with air to 2.5 atmospheres absolute (ATA) during $15 \mathrm{~min}$, then were supplied 100\% oxygen for $25 \mathrm{~min}$, followed by a 5-min air break. Repeats the cycle once, and then gives $100 \%$ oxygen for $10 \mathrm{~min}$, and then the chamber is depressurized to 1 ATA with $100 \%$ oxygen over $15 \mathrm{~min}$. The total treatment time was $100 \mathrm{~min}$.

\subsection{Blood Sampling, Assessment of Oxidative Stress and Adhesion Molecules}

Blood samples were collected from 10 acute TBI patients within 2 weeks after the injury, between the 8th and 10th weeks after the injury, and between the 16th and 18th weeks after the injury. Blood samples were collected into Vacutainer SST tubes (BD, Franklin Lakes, NJ, USA) by venipuncture. The blood was allowed to clot in room temperature for a minimum of $30 \mathrm{~min}$. All samples were collected after centrifugation at $3000 \mathrm{rpm}$ for $10 \mathrm{~min}$ at $4{ }^{\circ} \mathrm{C}$, isolated, and immediately stored in multiple aliquots at $-80^{\circ} \mathrm{C}$. The flow chart of patients recruited and treatments was on Figure 1.

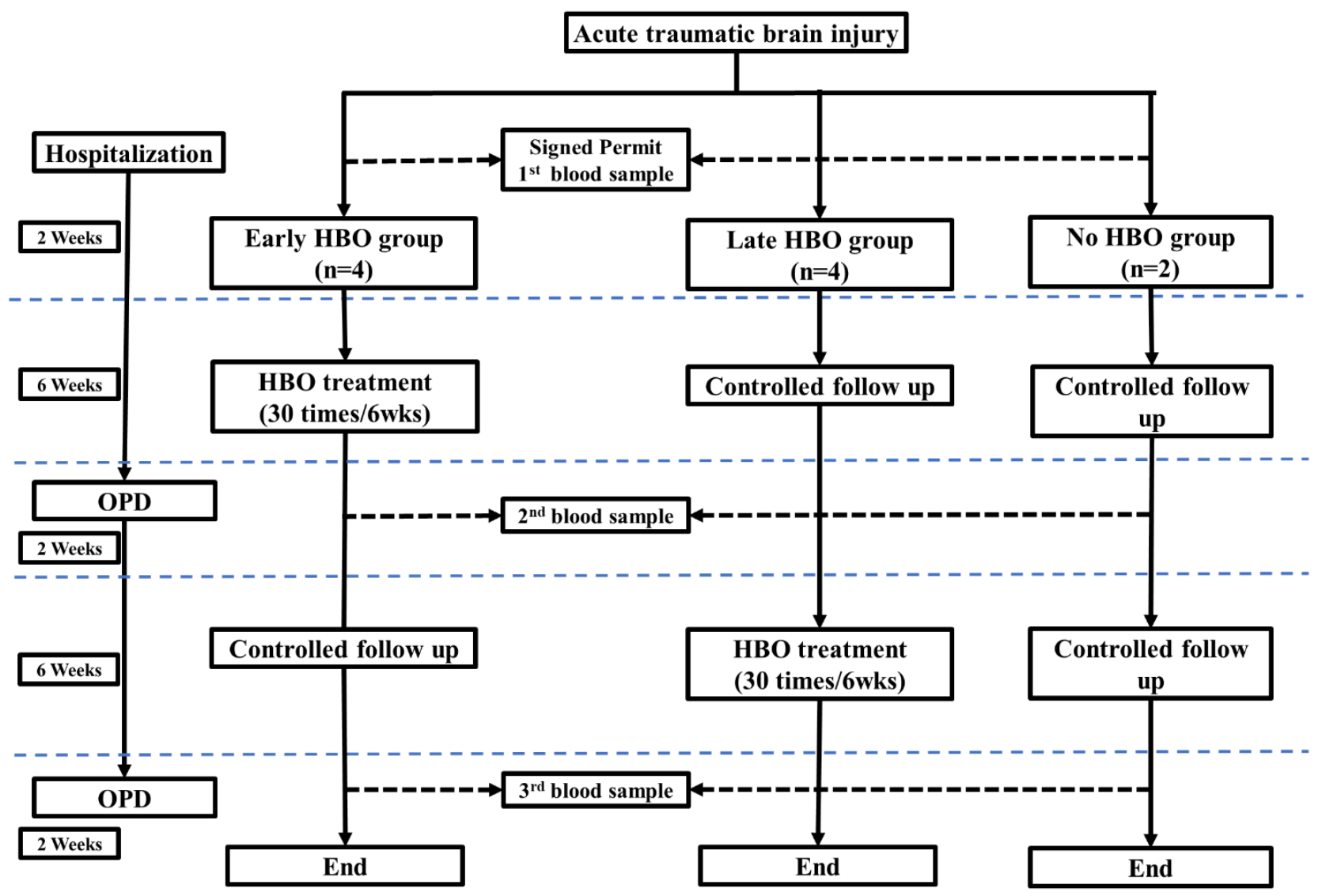

Figure 1. The flow chart of patients recruited and treatments.

\subsubsection{Serum Glutathione (GSH) Levels}

The serum total protein glutathione is estimated by the direct reaction of glutathione with 5,5-dithiobis-2-nitrobenzoic acid (DTNB) to form 5-thio-2-nitrobenzoic acid (TNB). 
The amount of glutathione in the sample is calculated from the absorbance using the extinction coefficient of TNB (A412 $=13,600 \mathrm{M}^{-1} \mathrm{~cm}^{-1}$ ). In this study, we used the GSH Assay Kit (catalog 703002; Cayman Chemical, Michigan, MI, USA).

\subsubsection{Serum Thiobarbituric Acid-Reactive Substances (TBARS) Levels}

In this study, the TBARS detection kit was used for rapid photometric detection of thiobarbituric acid-malonaldehyde (TBA-MDA) adducts at $532 \mathrm{~nm}$, as described by the manufacturer (catalog 10009055; Cayman Chemical, Michigan, MI, USA). The sample value is calculated from a linear calibration curve using pure MDA samples (range: 0-50 $\mu \mathrm{mol} / \mathrm{L}$ ).

2.3.3. Serum Soluble Intercellular Cell Adhesion-Molecule-1 (sICAM-1) Levels, and Serum Soluble Vascular Cell Adhesion Molecule-1 (sVCAM-1) Levels

The serum levels of sICAM-1 and SVCAM-1 were evaluated by a commercially available ELISA (R\&D Systems, Minneapolis, MN, USA). The absorbance is directly proportional to the concentration of antigen present. A set of antigen standards is used to draw a standard curve between absorbance and antigen concentration, from which the antigen concentration in the unknown is calculated.

\subsection{Clinical Manifestations}

The patients were also divided into three groups according HBOT: early HBOT group (received HBOT between 2 weeks and 8 weeks after injury), late HBOT (received HBOT between 10 weeks and 16 weeks after injury), and control group (did not receive HBOT).

Patients receive regularly monitor the Glasgow Coma Scale (GCS) score, and vital sign, keep fluid balance, and normalize laboratory parameters. Using the objective Injury Severity Score (ISS) on admission to calculate the total degree of injury [39]. All patients underwent brain CT scans in the emergency room. If clinical deterioration, such as acute onset of focal neurological deficits, seizures, status epilepticus, and progressive disturbance of consciousness, repetitive brain CT scans or/and magnetic resonance imaging (MRI) and as a routine after neurosurgery.

\subsection{Statistics}

Categorical data were analyzed by chi-square test or Fisher's exact test. Use Student's test or ANOVA to analyze continuous data. The data is the mean \pm standard derivation (SD) for normally distributed data. The SPSS 22.0 (SPSS Inc., Chicago, IL, USA) software was used for all statistical analyses.

\section{Results}

\subsection{Baseline Characteristics of the Study Patients}

According to the baseline characteristics of acute TBI cases (Table 1), the 10 acute TBI patients included 5 males (age range 21-48 years; median age 36 years) and 5 females (age range 27-70 years; average age, 57 years old). According to the GCS score at admission, 6 cases were mild, 1 case was moderate, and 3 cases were severe. The ISS on admission was 20. Three patients had moderate injuries (ISS 9-15), five had severe injuries (ISS 16-24), and two had very serious injuries (ISS > 24). Four patients (40\%) underwent neurosurgery within $24 \mathrm{~h}$ after TBI, of which three underwent craniotomy and one underwent intracranial pressure monitoring. The mean values of GCS score and ISS for patients undergoing neurosurgical treatment at admission were 11.5 and 24.8 , respectively. The most common CT findings at the time of presentation were parenchymal contusion hemorrhage (50\%), traumatic SAH (40\%) and subdural hemorrhage (40\%). 
Table 1. Demographic Data in Patients with Acute Traumatic Brain Injury at Admission.

\begin{tabular}{|c|c|c|c|c|}
\hline & $\begin{array}{c}\text { Early HBOT } \\
\quad(N=4)\end{array}$ & $\begin{array}{l}\text { Late HBOT } \\
\qquad(N=4)\end{array}$ & $\begin{array}{c}\text { No HBOT } \\
(N=2)\end{array}$ & $p$-Value \\
\hline Age (y) & $53 \pm 10.3$ & $41 \pm 10.9$ & $44 \pm 4$ & 0.708 \\
\hline BMI & $26.4 \pm 1.8$ & $25.2 \pm 1.1$ & $22.6 \pm 1.2$ & 0.346 \\
\hline Male & 2 & 2 & 1 & 0.223 \\
\hline \multicolumn{5}{|l|}{ Underlying diseases } \\
\hline Diabetes mellitus & 2 & 0 & 0 & 0.153 \\
\hline Hypertension & 2 & 1 & 0 & 0.435 \\
\hline Coronary artery disease & 0 & 0 & 0 & NA \\
\hline Alcoholism & 0 & 0 & 0 & NA \\
\hline Smoking & 0 & 0 & 0 & NA \\
\hline \multicolumn{5}{|l|}{ Clinical feature at presentation } \\
\hline Brief unconsciousness & 1 & 3 & 1 & 0.368 \\
\hline Motor deficits & 1 & 3 & 0 & 0.153 \\
\hline Posttraumatic amnesia & 1 & 3 & 0 & 0.153 \\
\hline GCS at presentation & $15 \pm 0$ & $8.5 \pm 0.9$ & $15 \pm 0$ & $\leq 0.001$ \\
\hline $\begin{array}{l}\text { Injury Severity Score at presentation } \\
\text { Laboratory data at presentation }\end{array}$ & $19.3 \pm 2.1$ & $19.8 \pm 3.7$ & $22.5 \pm 11.5$ & 0.9 \\
\hline WBC $\left(\times 10^{3} / \mathrm{mL}\right)$ & $11.4 \pm 1.9$ & $17.3 \pm 2.6$ & $15.1 \pm 1.8$ & 0.223 \\
\hline Hemoglobin (gm/dl) & $12.8 \pm 1.0$ & $12.1 \pm 1.2$ & $13.9 \pm 0.1$ & 0.611 \\
\hline Hematocrit & $38.9 \pm 3.1$ & $36.9 \pm 3.7$ & $42.0 \pm 0.5$ & 0.655 \\
\hline Platelet counts $\left(\times 10^{3} / \mathrm{mL}\right)$ & $230.2 \pm 14.9$ & $303.8 \pm 37.5$ & $228.5 \pm 10.5$ & 0.167 \\
\hline Prothrombin Time (PT) & $10.5 \pm 0.38$ & $10.8 \pm 0.43$ & $11.1 \pm 0.15$ & 0.701 \\
\hline $\begin{array}{l}\text { Activated partial thromboplastin time } \\
\text { (APTT) }\end{array}$ & $23.7 \pm 0.5$ & $25.7 \pm 1.9$ & $26.4 \pm 0.7$ & 0.432 \\
\hline \multicolumn{5}{|l|}{ Brain Imagies Findings at presentation } \\
\hline Parenchymal contusion hemorrhage & 2 & 3 & 0 & 0.223 \\
\hline Epidural hemorrhage & 2 & 1 & 1 & 0.732 \\
\hline Subdural hemorrhage & 2 & 2 & 0 & 0.435 \\
\hline Traumatic subarachnoid hemorrhage & 1 & 1 & 2 & 0.153 \\
\hline Depressed skull fracture & 0 & 0 & 0 & NA \\
\hline Pneumocranium & 0 & 0 & 0 & NA \\
\hline Neurosurgical intervention & 1 & 2 & 1 & 0.732 \\
\hline \multicolumn{5}{|l|}{ Oxidative Stress at presentation } \\
\hline Glutathione $(\mu \mathrm{mol} / \mathrm{L})$ & $0.96 \pm 0.15$ & $1.05 \pm 0.16$ & $1.03 \pm 0.17$ & 0.916 \\
\hline TBARS $(\mu \mathrm{mol} / \mathrm{L})$ & $16.92 \pm 1.40$ & $17.28 \pm 1.55$ & $17.12 \pm 0.19$ & 0.98 \\
\hline \multicolumn{5}{|l|}{$\begin{array}{l}\text { Soluble intercellular adhesion molecule at } \\
\text { presentation }\end{array}$} \\
\hline sICAM-1 $(\mathrm{ng} / \mathrm{mL})$ & $216 \pm 15$ & $246 \pm 17$ & $201 \pm 13$ & 0.306 \\
\hline sVCAM-1 (ng/mL) & $696 \pm 33$ & $690 \pm 16$ & $732 \pm 34$ & 0.548 \\
\hline \multicolumn{5}{|l|}{ Acute neurosurgical complications } \\
\hline Newly onset of neurological deficit & 0 & 0 & 0 & NA \\
\hline Deterioration of consciousness & 0 & 0 & 0 & NA \\
\hline Posttraumatic seizure & 0 & 0 & 0 & NA \\
\hline GOS at 10 wks follow-up & $5 \pm 0$ & $4.5 \pm 0.29$ & $5 \pm 0$ & 0.193 \\
\hline GOS at 18 wks follow-up & $5 \pm 0$ & $4.5 \pm 0.29$ & $5 \pm 0$ & 0.193 \\
\hline Days of ICU stay & $2.8 \pm 1.4$ & $3.8 \pm 1.3$ & $3 \pm 0$ & 0.848 \\
\hline Days of Hospitalization & $11.8 \pm 1.3$ & $25 \pm 5$ & $9 \pm 4$ & 0.134 \\
\hline
\end{tabular}

GCS, Glasgow coma scale; SD, standard derivation; TBARS, thiobarbituric acid-reactive substances; sICAM-1, soluble intercellular adhesion molecule; sVCAM-1, soluble vascular cell adhesion molecule GOS, Glasgow outcome scale; ICU, intensive care unit. Data are presented either as absolute numbers or mean \pm standard derivation (SD). Statistical significance was set at a level of $p=0.05$. Statistical variance between groups was assessed by the Fisher's exact test for discrete variables and by Student's $t$ test or ANOVA test for continuous variables.

Comparison of these three groups, early HBOT, late HBOT and no HBOT, at admission, there were not significantly difference at baseline data, except worse GCS in the late HBOT group (Table 1). Those serum biomarkers in patients with TBI had not significantly difference in Glutathione, TBARS, sICAM- 1 and sVCAM- 1 concentrations on admission $(p=0.916, p=0.98, p=0.306$, and $p=0.548$, respectively) (Table 1$)$. 


\subsection{The Time Course of Oxidative Stress and Serum Adhesion Molecules Concentration Changes}

The time course of oxidative stress and serum adhesion molecules concentration changes in acute TBI patients with early and late HBOT was compared. Serum GSH levels were higher at 10 weeks after injury in the early HBOT group than in the late HBOT group and control group (mean, $1.40 \mu \mathrm{mol} / \mathrm{L}, 1.16 \mu \mathrm{mol} / \mathrm{L}$, and $1.05 \mu \mathrm{mol} / \mathrm{L}$, respectively). Then the serum GSH level was increased at 18 weeks after injury in the late HBOT group (mean, $1.49 \mu \mathrm{mol} / \mathrm{L}$ ). However, there was no statistically significant difference at Weeks 18 ( $p=0.916, p=0.463$, and $p=0.060$, at Week 2 , Week 10, and Week 18, respectively) (Figure 2A). Serum TBARS levels were decreased at 10 weeks after injury in the early HBOT group than in the late HBOT group and control group (mean, $11.21 \mu \mathrm{mol} / \mathrm{L}$, $17.23 \mu \mathrm{mol} / \mathrm{L}$, and $17.14 \mu \mathrm{mol} / \mathrm{L}$, respectively). Then the serum TBARS level was decreased at 18 weeks after injury in the late HBOT group (mean, $12.06 \mu \mathrm{mol} / \mathrm{L}$ ). There was statistically significant difference after HBOT $(p=0.98, p=0.007$, and $p=0.018$, at Week 2, Week 10, and Week 18, respectively) (Figure 2B). Post-hoc test showed early HBOT was statistically significant difference on late HBOT $(p=0.013)$ and control group $(p=0.021)$ at Week 10, and control group was statistically significant difference on late HBOT $(p=0.035)$ and early HBOT $(p=0.031)$ at Week 18 . There was no statistically significant difference between the three groups on sICAM- 1 and sVCAM-1 levels from Week 2 to Week 18 (Figure 3A,B).

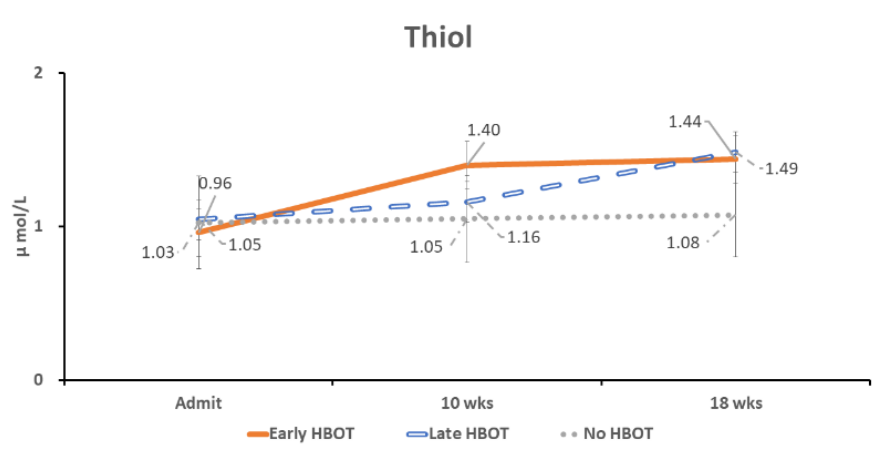

(A)

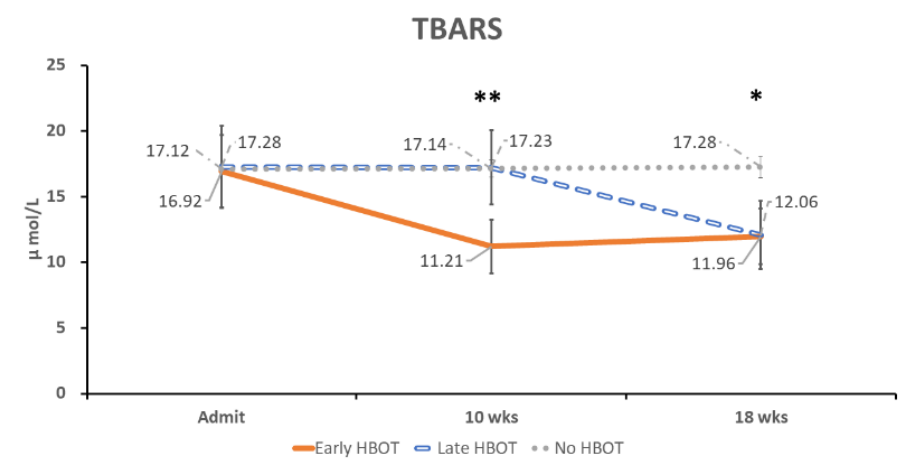

(B)

Figure 2. The time course of serum oxidative stress concentration changes in (A) GSH, and (B) TBARS at Week 2, Week 10, and Week 18 in patients with acute TBI who received early HBOT, late HBOT and control group. ${ }^{*} p<0.05,{ }^{* *} p<0.01$, between early HBOT group, late HBOT group and control group, by ANOVA.

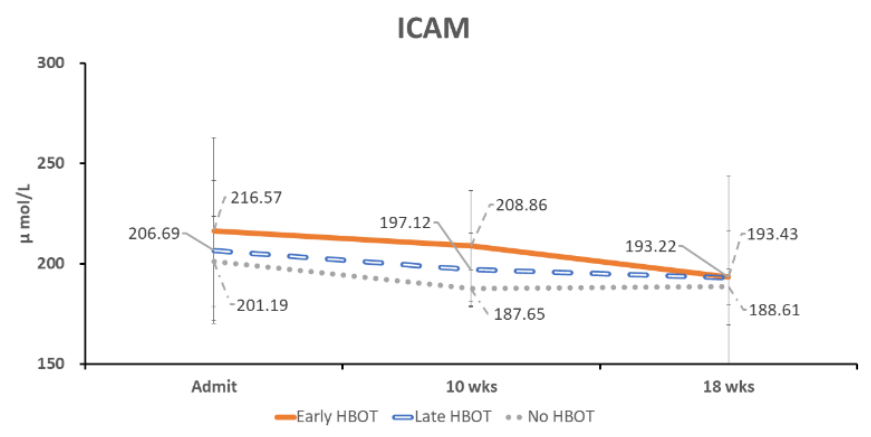

(A)

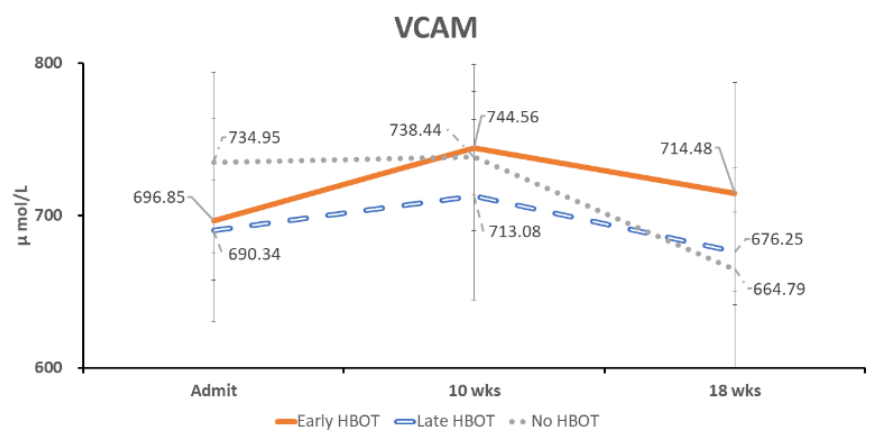

(B)

Figure 3. The time course of serum adhesion molecular concentration changes in (A) sICAM-1, and (B) sVCAM-1 at Week 2, Week 10, and Week 18 in patients with acute TBI who received early HBOT, late HBOT and control group.

By GOS upon discharge of the 10 acute TBI patients, six had no disability, four had moderated disability. There was no statistically significant difference between the 
three groups on Week 10 and Week 18 following-up ( $p=0.193$ and $p=0.193$, at Week 10 and Week 18, respectively).

\section{Discussion}

This study examined the correlation between HBOT and markers of oxidative stress and endothelial cell activation after acute TBI. There are several main findings. First, compared with the control group, the oxidative stress concentration of GSH and TBARS in the HBOT group was significantly increased after HBOT. Secondly, plasma sICAM-1 and sVCAM-1 levels did not change significantly after HBOT. Third, comparing the treatment results of acute TBI cases based on GOS, there was no significant difference in HBOT between the three groups.

\subsection{Oxidative Stress in TBI Patients}

GSH is an endogenous antioxidant that can protect endothelial function and increase the bioavailability of nitric oxide in neurovascular units after acute injury. The brain GSH level after TBI measured $24 \mathrm{~h}$ after cortical contusion in rats was significantly lower than that of control brains [40,41]. Compared to the control group, serum GSH level was increased at 10 weeks in the early HBOT group and persisted to Week 18. This meant that GSH was triggered and persisted for at least eight weeks after HBOT. The serum GSH level was increased at 18 weeks in the late HBOT group. In contrast, the serum GSH level was no significant changed in control (TBI but no HBOT) group. HBOT did increase serum GSH level, however, there was only statistically significant difference at Weeks 18 between these three groups $(p=0.916, p=0.463$, and $p=0.006$, at Week 2, Week 10, and Week 18, respectively) (Figure 2A). However, in Bayir et al. study showed that compared with the control group, GSH levels increased on day 1, and then decreased in severe TBI [42]. This posits that GSH is triggered in the early stage of TBI, at least on Day 1, and then decreases thereafter.

In the present study, HBOT did increase serum GSH level, however, there was only statistically significant difference at Weeks 18 between these three groups $(p=0.916, p=0.463$, and $p=0.006$, at Week 2, Week 10, and Week 18, respectively) (Figure 2A). Bayir et al. another study of 13 severe pediatric TBI patients with therapeutic hypothermia showed that hypothermia can preserve CSF antioxidant reserves [43]. The study also showed that the level of GSH in CSF was negatively correlated with the patient's body temperature at the time of sampling after injury. Different results of Bayir et al. 2002, and present study may be due to different disease severity (severe TBI in Bayir's study, and mainly mild TBI in this study), different samples (cerebrospinal fluid and plasma), or different patient ages (children and aldult).

Serum TBARS levels was significant decreased at 10 weeks in the early HBOT group and persisted to Week 18. This meant that TBARS was supressed and persisted for at least eight weeks after HBOT. Then the serum TBARS level was decreased at 18 weeks after injury in the late HBOT group. There was statistically significant difference after HBOT ( $p=0.98, p=0.007$, and $p=0.018$, at Week 2, Week 10, and Week 18, respectively) (Figure 2B).

In the study of Kasprzak et al., compared with the control group, during the 10-day follow-up period, the CSF erythrocyte TBARS concentration of brain contusion patients increased significantly [44]. The highest CSF TBARS concentration was observed in 5 patients who died 2, 7, or 8 days after head injury. The results of the current study demonstrates that the HBOT group has significantly improved oxidative stress concentrations of GSH and TBARS after HBOT.

\subsection{Adhesion Molecules in TBI Patients}

Soluble adhesion molecules has been proposed to inhibit the ongoing immune inflammatory response by competitive binding or by inducing the response of ligand-bearing cells [45]. The endothelium promotes inflammatory cells to enter the brain parenchyma, 
which depends on the expression and regulation of paired adhesion molecules presenting on infiltrating leukocytes and cerebral vascular endothelial cells $[46,47]$.

The level of serum sICAM-1 in patients with multiple injuries is elevated, which is related to the severity of organs dysfunction [48]. Adhesion molecules play an important role in the process of inflammation and may play different roles in different conditions. One animal study using ICAM-1-deficient mutant mice has shown that ICAM-1 does not cause the pathogenesis of TBI [49]. However, some studies have shown that circulating sICAM-1 and sVCAM-1 levels are elevated in patients with acute TBI, and SVCAM-1 levels are significantly elevated in TBI patients with poor outcome [27].

\subsection{Study Limitations}

The current study has several limitations. First, serum GSH and TBARS levels are only part of the oxidative stress expressed after TBI. Therefore, the change levels of these markers may not necessarily reflect their actual pathophysiological functions. Second, different medical treatments by different doctors during HBOT may be a confounding factor. Third, the sample size is small. This may lead to potential deviations in statistical analysis or accidental statistical discoveries. Last, the Glasgow Outcome Score (GOS) is a very blunt instrument, and unlikely to show a functional effect of treatment, particularly in such a small sample.

\section{Conclusions}

The HBOT group has significantly improved oxidative stress concentrations of GSH and TBARS after HBOT and persisted for at least eight weeks. However, HBOT did not improve plasma sICAM-1 and sVCAM-1 levels. In clinical practice, the measurement of such molecules can be added to the trauma parameter as evaluation markers. Serum oxidative stress concentration may be a potential therapeutic target for patients with TBI. Nevertheless, a large-scale study with a larger research population should be conducted to verify the results.

Author Contributions: Conceptualization, H.-C.W., P.-M.W. and C.-H.L.; methodology, H.-C.W., P.-M.W. and Y.-T.L.; formal analysis, N.-W.T. and Y.-R.L.; investigation, P.-M.W. and Y.-T.L.; resources, H.-C.W., C.-M.S. and C.-T.K.; writing-original draft preparation, H.-C.W.; writing-review and editing, C.-H.L.; supervision, C.-H.L.; project administration, C.-H.L.; funding acquisition, H.-C.W. All authors have read and agreed to the published version of the manuscript.

Funding: Funding: This research was funded by grants from the Chang Gung Memorial Hospital Research Project (CMRPG8J0151).

Institutional Review Board Statement: The study was conducted according to the guidelines of the Declaration of Helsinki, and approved by the Institutional Review Board of Chang Gung Medical Foundation (protocol code 201801854A3 on 4 January 2019).

Informed Consent Statement: Informed consent was obtained from all subjects involved in the study.

Conflicts of Interest: The authors declare no conflict of interest.

\section{References}

1. Lenzlinger, P.M.; Morganti-Kossmann, M.C.; Laurer, H.L.; McIntosh, T.K. The duality of the inflammatory response to traumatic brain injury. Mol. Neurobiol. 2001, 24, 169-181.

2. Zhang, X.; Chen, Y.; Jenkins, L.W.; Kochanek, P.M.; Clark, R.S. Bench-to-bedside review: Apoptosis/programmed cell death triggered by traumatic brain injury. Crit. Care 2005, 9, 66-75. [CrossRef]

3. Chong, Z.Z.; Li, F.; Maiese, K. Oxidative stress in the brain: Novel cellular targets that govern survival during neurodegenerative disease. Prog. Neurobiol. 2005, 75, 207-246. [CrossRef]

4. Yu, F.; Xue, W.; Dong, L.; Hu, X.; Huang, D.; Wang, K. Tetrahydroxystilbene glucoside suppresses napdh oxidative stress to mitigate apoptosis and autophagy induced by cerebral ischemia/reperfusion injury in mice. Evid. Based Complement. Altern. Med. 2019, 2019, 3913981. [CrossRef] [PubMed]

5. Chandravanshi, L.P.; Gupta, R.; Shukla, R.K. Developmental neurotoxicity of arsenic: Involvement of oxidative stress and mitochondrial functions. Biol. Trace Elem. Res. 2018, 186, 185-198. [CrossRef] [PubMed] 
6. Herbert, V.; Shaw, S.; Jayatilleke, E.; Stopler-Kasdan, T. Most free-radical injury is iron-related: It is promoted by iron, hemin, holoferritin and vitamin c, and inhibited by desferoxamine and apoferritin. Stem Cells 1994, 12, 289-303. [CrossRef] [PubMed]

7. Floyd, R.A.; Carney, J.M. Free radical damage to protein and DNA: Mechanisms involved and relevant observations on brain undergoing oxidative stress. Ann. Neurol. 1992, 32, S22-S27. [CrossRef]

8. Kontos, H.A.; Wei, E.P. Superoxide production in experimental brain injury. J. Neurosurg. 1986, 64, 803-807. [CrossRef] [PubMed]

9. Hall, E.D.; Andrus, P.K.; Yonkers, P.A. Brain hydroxyl radical generation in acute experimental head injury. J. Neurochem. 1993, 60, 588-594. [CrossRef] [PubMed]

10. Smith, S.L.; Andrus, P.K.; Zhang, J.R.; Hall, E.D. Direct measurement of hydroxyl radicals, lipid peroxidation, and blood-brain barrier disruption following unilateral cortical impact head injury in the rat. J. Neurotrauma 1994, 11, 393-404. [CrossRef]

11. Fan, L.M.; Geng, L.; Cahill-Smith, S.; Liu, F.; Douglas, G.; McKenzie, C.A.; Smith, C.; Brooks, G.; Channon, K.M.; Li, J.M. Nox2 contributes to age-related oxidative damage to neurons and the cerebral vasculature. J. Clin. Investig. 2019, 129, 3374-3386. [CrossRef] [PubMed]

12. Yang, X.; Wang, Y.; Li, Q.; Zhong, Y.; Chen, L.; Du, Y.; He, J.; Liao, L.; Xiong, K.; Yi, C.X.; et al. The main molecular mechanisms underlying methamphetamine- induced neurotoxicity and implications for pharmacological treatment. Front. Mol. Neurosci. 2018, 11, 186. [CrossRef]

13. Shin, E.J.; Tran, H.Q.; Nguyen, P.T.; Jeong, J.H.; Nah, S.Y.; Jang, C.G.; Nabeshima, T.; Kim, H.C. Role of mitochondria in methamphetamine-induced dopaminergic neurotoxicity: Involvement in oxidative stress, neuroinflammation, and pro-apoptosisa review. Neurochem. Res. 2018, 43, 66-78. [CrossRef]

14. Barbosa, D.J.; Capela, J.P.; Feio-Azevedo, R.; Teixeira-Gomes, A.; Bastos Mde, L.; Carvalho, F. Mitochondria: Key players in the neurotoxic effects of amphetamines. Arch. Toxicol. 2015, 89, 1695-1725. [CrossRef]

15. Zhang, Z.W.; Liang, J.; Yan, J.X.; Ye, Y.C.; Wang, J.J.; Chen, C.; Sun, H.T.; Chen, F.; Tu, Y.; Li, X.H. Tbhq improved neurological recovery after traumatic brain injury by inhibiting the overactivation of astrocytes. Brain Res. 2020, 1739, 146818. [CrossRef]

16. Lu, J.; Goh, S.J.; Tng, P.Y.; Deng, Y.Y.; Ling, E.A.; Moochhala, S. Systemic inflammatory response following acute traumatic brain injury. Front. Biosc. 2009, 14, 3795-3813. [CrossRef]

17. Stein, S.C.; Smith, D.H. Coagulopathy in traumatic brain injury. Neurocrit. Care 2004, 1, 479-488. [CrossRef]

18. Lehnardt, S. Innate immunity and neuroinflammation in the cns: The role of microglia in toll-like receptor-mediated neuronal injury. Glia 2010, 58, 253-263. [CrossRef]

19. Rhind, S.G.; Crnko, N.T.; Baker, A.J.; Morrison, L.J.; Shek, P.N.; Scarpelini, S.; Rizoli, S.B. Prehospital resuscitation with hypertonic saline-dextran modulates inflammatory, coagulation and endothelial activation marker profiles in severe traumatic brain injured patients. J. Neuroinflamm. 2010, 7, 5. [CrossRef] [PubMed]

20. Bednar, M.M.; Gross, C.E.; Howard, D.B.; Lynn, M. Neutrophil activation in acute human central nervous system injury. Neurol. Res. 1997, 19, 588-592. [CrossRef] [PubMed]

21. Carson, M.J.; Thrash, J.C.; Walter, B. The cellular response in neuroinflammation: The role of leukocytes, microglia and astrocytes in neuronal death and survival. Clin. Neurosci. Res. 2006, 6, 237-245. [CrossRef]

22. Kadhim, H.J.; Duchateau, J.; Sebire, G. Cytokines and brain injury: Invited review. J. Intensive Care Med. 2008, 23, 236-249. [CrossRef]

23. Lee, S.J.; Benveniste, E.N. Adhesion molecule expression and regulation on cells of the central nervous system. J. Neuroimmunol. 1999, 98, 77-88. [CrossRef]

24. Soriano, S.G.; Piva, S. Central nervous system inflammation. Eur. J. Anaesthesiol. Suppl. 2008, 42, 154-159. [CrossRef] [PubMed]

25. Balabanov, R.; Goldman, H.; Murphy, S.; Pellizon, G.; Owen, C.; Rafols, J.; Dore-Duffy, P. Endothelial cell activation following moderate traumatic brain injury. Neurol. Res. 2001, 23, 175-182. [CrossRef] [PubMed]

26. Langer, H.F.; Chavakis, T. Leukocyte-endothelial interactions in inflammation. J. Cell Mol. Med. 2009, 13, 1211-1220. [CrossRef]

27. Wang, H.C.; Wang, P.M.; Lin, Y.J.; Kwan, A.L.; Lin, W.C.; Tsai, N.W.; Cheng, B.C.; Chang, W.N.; Su, B.Y.; Kung, C.T.; et al. Serum adhesion molecules, outcome and neuro-psychological function in acute traumatic brain injury patients. Clin. Chim. Acta 2013, 423, 122-129. [CrossRef] [PubMed]

28. McKeating, E.G.; Andrews, P.J.; Mascia, L. The relationship of soluble adhesion molecule concentrations in systemic and jugular venous serum to injury severity and outcome after traumatic brain injury. Anesth. Analg. 1998, 86, 759-765. [PubMed]

29. Zhou, B.C.; Liu, L.J.; Liu, B. Neuroprotection of hyperbaric oxygen therapy in sub-acute traumatic brain injury: Not by immediately improving cerebral oxygen saturation and oxygen partial pressure. Neural. Regen. Res. 2016, 11, 1445-1449. [PubMed]

30. Chazalviel, L.; Haelewyn, B.; Degoulet, M.; Blatteau, J.E.; Vallee, N.; Risso, J.J.; Besnard, S.; Abraini, J.H. Hyperbaric oxygen increases tissue-plasminogen activator-induced thrombolysis in vitro, and reduces ischemic brain damage and edema in rats subjected to thromboembolic brain ischemia. Med. Gas. Res. 2016, 6, 64-69.

31. Rockswold, S.B.; Rockswold, G.L.; Zaun, D.A.; Zhang, X.; Cerra, C.E.; Bergman, T.A.; Liu, J. A prospective, randomized clinical trial to compare the effect of hyperbaric to normobaric hyperoxia on cerebral metabolism, intracranial pressure, and oxygen toxicity in severe traumatic brain injury. J. Neurosurg. 2010, 112, 1080-1094. [CrossRef]

32. Wolf, G.; Cifu, D.; Baugh, L.; Carne, W.; Profenna, L. The effect of hyperbaric oxygen on symptoms after mild traumatic brain injury. J. Neurotrauma 2012, 29, 2606-2612. [CrossRef] [PubMed] 
33. Boussi-Gross, R.; Golan, H.; Fishlev, G.; Bechor, Y.; Volkov, O.; Bergan, J.; Friedman, M.; Hoofien, D.; Shlamkovitch, N.; Ben-Jacob, E.; et al. Hyperbaric oxygen therapy can improve post concussion syndrome years after mild traumatic brain injury—randomized prospective trial. PLoS ONE 2013, 8, e79995. [CrossRef] [PubMed]

34. Walker, W.C.; Franke, L.M.; Cifu, D.X.; Hart, B.B. Randomized, sham-controlled, feasibility trial of hyperbaric oxygen for service members with postconcussion syndrome: Cognitive and psychomotor outcomes 1 week postintervention. Neurorehabil. Neural. Repair. 2014, 28, 420-432. [CrossRef] [PubMed]

35. Daugherty, W.P.; Levasseur, J.E.; Sun, D.; Rockswold, G.L.; Bullock, M.R. Effects of hyperbaric oxygen therapy on cerebral oxygenation and mitochondrial function following moderate lateral fluid-percussion injury in rats. J. Neurosurg. 2004, 101, 499-504. [CrossRef] [PubMed]

36. Palzur, E.; Zaaroor, M.; Vlodavsky, E.; Milman, F.; Soustiel, J.F. Neuroprotective effect of hyperbaric oxygen therapy in brain injury is mediated by preservation of mitochondrial membrane properties. Brain Res. 2008, 1221, 126-133. [CrossRef] [PubMed]

37. Palzur, E.; Vlodavsky, E.; Mulla, H.; Arieli, R.; Feinsod, M.; Soustiel, J.F. Hyperbaric oxygen therapy for reduction of secondary brain damage in head injury: An animal model of brain contusion. J. Neurotrauma. 2004, 21, 41-48. [CrossRef]

38. Harch, P.G.; Kriedt, C.; Van Meter, K.W.; Sutherland, R.J. Hyperbaric oxygen therapy improves spatial learning and memory in a rat model of chronic traumatic brain injury. Brain Res. 2007, 1174, 120-129. [CrossRef]

39. Baker, S.P.; O’Neill, B.; Haddon, W., Jr.; Long, W.B. The injury severity score: A method for describing patients with multiple injuries and evaluating emergency care. J. Trauma. 1974, 14, 187-196. [CrossRef]

40. Khan, M.; Sakakima, H.; Dhammu, T.S.; Shunmugavel, A.; Im, Y.B.; Gilg, A.G.; Singh, A.K.; Singh, I. S-nitrosoglutathione reduces oxidative injury and promotes mechanisms of neurorepair following traumatic brain injury in rats. J. Neuroinflamm. 2011, 8, 78. [CrossRef]

41. Tyurin, V.A.; Tyurina, Y.Y.; Borisenko, G.G.; Sokolova, T.V.; Ritov, V.B.; Quinn, P.J.; Rose, M.; Kochanek, P.; Graham, S.H.; Kagan, V.E. Oxidative stress following traumatic brain injury in rats: Quantitation of biomarkers and detection of free radical intermediates. J. Neurochem. 2000, 75, 2178-2189. [CrossRef] [PubMed]

42. Bayir, H.; Kagan, V.E.; Tyurina, Y.Y.; Tyurin, V.; Ruppel, R.A.; Adelson, P.D.; Graham, S.H.; Janesko, K.; Clark, R.S.; Kochanek, P.M. Assessment of antioxidant reserves and oxidative stress in cerebrospinal fluid after severe traumatic brain injury in infants and children. Pediatr. Res. 2002, 51, 571-578. [CrossRef]

43. Bayir, H.; Adelson, P.D.; Wisniewski, S.R.; Shore, P.; Lai, Y.; Brown, D.; Janesko-Feldman, K.L.; Kagan, V.E.; Kochanek, P.M. Therapeutic hypothermia preserves antioxidant defenses after severe traumatic brain injury in infants and children. Crit. Care Med. 2009, 37, 689-695. [CrossRef]

44. Kasprzak, H.A.; Wozniak, A.; Drewa, G.; Wozniak, B. Enhanced lipid peroxidation processes in patients after brain contusion. J. Neurotrauma 2001, 18, 793-797. [CrossRef] [PubMed]

45. Giddings, J.C. Soluble adhesion molecules in inflammatory and vascular diseases. Biochem. Soc. Trans. 2005, 33, 406-408. [CrossRef] [PubMed]

46. Engelhardt, B. Immune cell entry into the central nervous system: Involvement of adhesion molecules and chemokines. J. Neurol. Sci. 2008, 274, 23-26. [CrossRef]

47. McKeating, E.G.; Andrews, P.J. Cytokines and adhesion molecules in acute brain injury. Br. J. Anaesth. 1998, 80, 77-84. [CrossRef]

48. Law, M.M.; Cryer, H.G.; Abraham, E. Elevated levels of soluble icam-1 correlate with the development of multiple organ failure in severely injured trauma patients. J. Trauma 1994, 37, 100-109, discussion 109-110. [CrossRef]

49. Whalen, M.J.; Carlos, T.M.; Dixon, C.E.; Schiding, J.K.; Clark, R.S.; Baum, E.; Yan, H.Q.; Marion, D.W.; Kochanek, P.M. Effect of traumatic brain injury in mice deficient in intercellular adhesion molecule-1: Assessment of histopathologic and functional outcome. J. Neurotrauma 1999, 16, 299-309. [CrossRef] 